\title{
Ultrastructure of spermiogenesis and spermatozoa of Pricea sp. (Monogenea, Polyopithocotylea, Gasterocotylidae), a gill parasite of Scomberomorus commerson (Pisces: Scomridae ) in Egypt
}

\author{
Khidr AA ${ }^{\mathrm{a}, *}$, Bahnasawy $\mathrm{MH}^{\mathrm{a}}$, Bakoosh $\mathrm{FE}^{\mathrm{b}}$ \\ ${ }^{a}$ Department of zoology, Faculty of Science, University of Damietta, Egypt \\ ${ }^{\mathrm{b}}$ Department of Aquatic Biology, Faculty of Science, University of Markab, Libya
}

Received: 1 Februry 2015 / Accepted: 28 March 2015

* Corresponding author (Phone: +20 1228708701; Fax: +20 572403868; E-mail: drakhidr@ gmail.com)

\begin{abstract}
The ultrastructure of the mature spermatozoon of polyopithocotylean Pricea sp., a parasite of Scomberomorus commerson was studied by transmission electron microscopy. The spermatozoon is composed of two parallel axonemes, of the $9+$ "1" pattern, one mitochondrion, a nucleus, cortical microtubules. The main characteristics of this spermatozoon are the presence of one mitochondrion, the two axonemes, which are of unequal length, and the cortical microtubules extend almost the entire length of the spermatozoon. The present study indicated that spermatogenesis is connected to a common cytophore. Spermiogenesis and the structure of the filiform sperm of Pricea sp conform to the typical polyopisthocotylean pattern. Ultrastructural features are also discussed and compared to other the monogeneans.
\end{abstract}

Keywords: Platyhelminthes, Monogenea, TEM, spermatogenesis, spermatozoon

\section{Introduction}

Comparative spermatology is great contribution to interpret phylogeny of platyhelminths. Therefore, to understand the relationships between species and their phylogeny, research can be carried out only on extant taxa, and has included both morphological and ultrastructural data (Brooks et al., 1985; Ehlers, 1985; Brooks, 1989; Rohde, 1990; Brooks and McLennan, 1993; Hoberg et al., 1997, Justine, 2001; $\mathrm{Ba}^{\wedge}$ et al., 2011), and more recently, molecular analysis (Littlewood et al., 1998; Olson et al., 2003; Olson and Tkach, 2005). Ultrastructural studies have identified distinct patterns of spermatogenesis amongst higher taxa and morphological variations in sperm structure 
have been used to distinguish species (reviews by Justine 1991a, b, 1993a). The ultrastructural characters of the male reproductive system, and especially the spermatozoon (e.g., the structure [the $9+$ "1" pattern of Trepaxonemata], the number of axonemes, the number of mitochondria, and the spiralled or parallel disposition of cortical microtubules), have been utilized for the estimation of phylogenies based only on these characters (Euzet et al., 1981; Justine et al., 1985; Justine, 1991a, 1997; Ba and Marchand, 1995; Levron et al., 2010). Within the Monogenea, most variation in sperm structure occurs within the Monopisthocotylea (three distinct patterns) and there is much greater uniformity by Justine 1993a). For comprehensive phylogenetic studies, it is important to extend the number of species analysed (Justine 1993b). Polyopisthocotylean sperm morphology has been examined in taxa representative of 17 of the 32 families recognised by Boeger and Kritsky (1993) (see Justine 1995). Among the Discocotylinea, sperm structure has been examined in two of the six families, and this includes the highly aberrant aflagellate sperm of Diplozoon gracile, in addition to the more typical sperm of Diclidophora merlangi and Choricotyle pagelli (review in Justine 1995). The aim of the present study is to compare the ultrastructure of the spermatozoon of Pricea sp. with that of the other parasitic flatworms in general and monogeneans in particular in terms of the principal criteria used in the phylogeny of the Platyhelminthes. Moreover, we hoped to distinguish ultrastructural characteristics that could be used in monogenean phylogeny.

\section{Materials and methods}

Live specimens of polyopithocotylean Pricea sp. were isolated from the gills of fish specimens of Scomberomorus commerson caught by trammel nets from Mediterranean sea at Raass Elbar City, Egypt. Live specimens of polyopithocotylean Pricea sp. were isolated from the gill filaments and washed in filtered sea water. They were kept for 30 minutes in the refrigerator (at about $4^{\circ} \mathrm{C}$ ) fixed for 3-4 hours in cold $\left(4^{\circ} \mathrm{C}\right) 4 \%$ glutaraldehyde in 0.2 $\mathrm{M}$ sodium cacodylate buffer at $\mathrm{pH}$ 7.4. The specimens were rinsed in $0.2 \mathrm{M}$ sodium cacodylate buffer at $\mathrm{pH} 7.4$, post-fixed in cold $\left(4^{\circ} \mathrm{C}\right) 1 \% \mathrm{OsO} 4$ in the same buffer for $1 \mathrm{~h}$, dehydrated in graded series of ethanol and propylene oxide, and embedded in Spur resin. Ultrathin sections (60-90 $\mathrm{nm}$ in thickness) were cut on a Leica Ultracut UCT ultramicrotome, placed on copper grids, and double-stained with uranyl acetate and lead citrate according to Reynolds (1963). Grids were examined under a JEOL 1010 transmission electron microscope at $80 \mathrm{kV}$.

\section{Results}

The morphology of Pricea sp. by transmission electron microscopy shows that the testes of Pricea $\mathrm{sp}$ is composed of numerous follicles, located in the posterior half of the body between the intestinal caeca. Each follicle includes different stages of cellular development of spermatogenesis. The primary spermatogonia are often found at the periphery of each follicle and produce primary spermatocytes by mitotic divisions. The secondary spermatocytes are formed also, by the mitotic divisions. The spermatids are produced by meiosis from the spermatocytes and each one differentiates into a mature spermatozoon.

\section{Spermatogonia}

The spermatogonia nuclei appear oval or elongated with dense spots of chromatin distributed throughout the nucleoplasm. (Fig. 1). The nucleus contains irregular clumps of heterochromatin scattered throughout a nucleoplasm. Few ribosomes are attached to the nuclear envelope. The cytoplasm matrix is electron dense due the presence of ribosomes, disposed in rosettes or polysome-like. Mitochondria and cisternae of endoplasmatic reticulum are present in cytoplasm (Figs 2,6). Transmission electron microscopy indicated that differentiating spermatids are connected by a single cytophore (Fig. 5). The spermatids are tightly compressed, therefore, the precise number of them in a cluster is not known, but 64 differentiating spermatids are recorded in other polyopisthocotyleans. During spermiogenesis, conformational changes occur in the chromatin and nucleus shape of early spermatid (Figs.2, 4, 7). Mitochondria are enlarged with short cisternae and they may contain lamellar whorls. Sheets of ER 
and free ribosomes are abundant in the electronlucent granular cytoplasm (Fig.2). The nucleus decreases in volume, chromatin condenses into lamellae which become organized into scroll-like twisted configurations interspersed with interchromatin granules (Fig.7). Further elongation of this outgrowth in the zone of differentiation (ZD) results in formation of the spermatozoan cell body. The centrioles give rise to two free flagellae, and meanwhile the two striated rootlets (Fig.3) .Two basal bodies develop either side of an intercentriolar body (Fig.5).

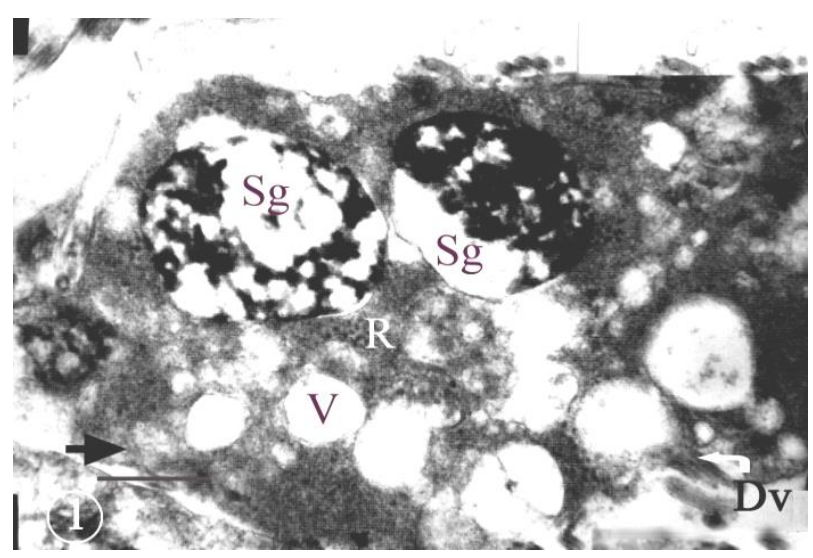

Fig. 1 Spermatogenesis of Pricea sp. Spermatogonia $(\mathrm{Sg})$ in periphery of the testes, showing heterochromatic nuclei $(\mathrm{N})$, endoplasmatic reticulum cisternae (black arrow), free ribosomes (R) and large vesicle (v), developing spermatid (Dv). Scale bar $=0.5 \mu \mathrm{m}$.

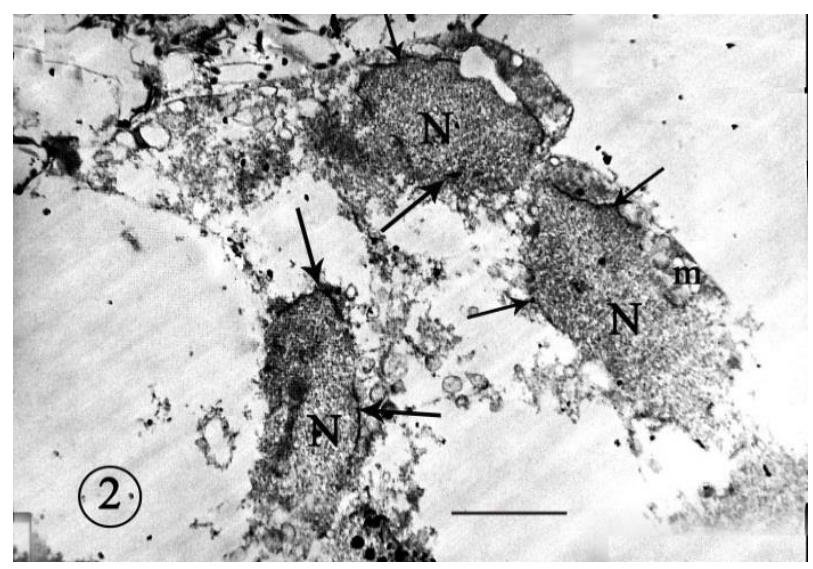

Fig. 2. Spermiogenesis of Pricea sp.. Early spermatid with prominent nucleus $(\mathrm{N})$, the nuclear envelope is thick on the external side ( arrows ) and mitochondria (m) cluster. Spermatid nucleus undergoing initial stages of elongation. Scale bar $=0.5 \mu \mathrm{m}$.

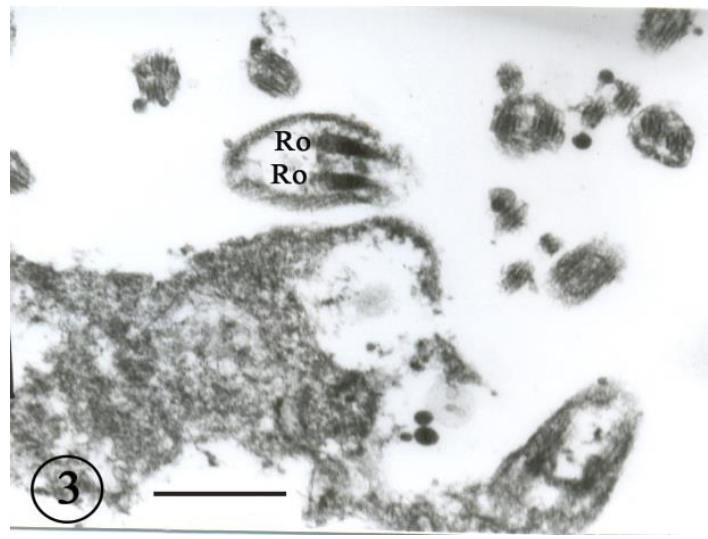

Fig.3. Spermiogenesis of Pricea sp. A: transversal and longitudinal sections of spermatids at the zone of differentiation showing lateral roots (Ro) of spermatid. Scale bar $=1 \mu \mathrm{m}$.

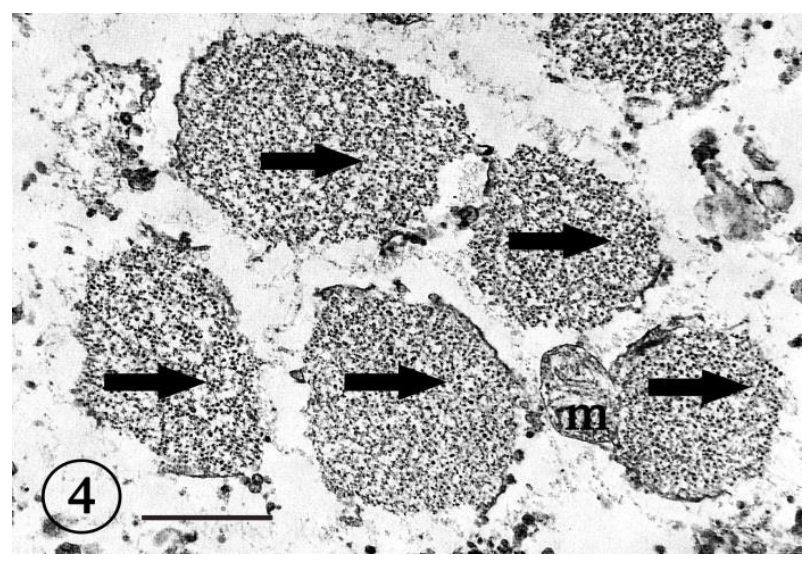

Fig. 4. Spermiogenesis of Pricea sp.: Transverse sections of spermatids nuclei, presenting lamellar and granular chromatin (arrows), and mitochondria (m) . Scale bar $=0.5 \mu \mathrm{m}$.

\section{Mature spermatozoa}

The sperm of Pricea sp. is filiform and conforms to the typical polyopisthocotylean pattern, i.e, composed of two parallel axonemes, mitochondrion, nucleus and cortical microtubules. Two axonemes (Figs.8, 11, 12) extend the majority of the length of the spermatozoon, but they are of slightly unequal length, one extending further the other. Each axoneme consists of 9 peripheral doublets of microtubules surrounding a central core, the so called 9+ "1" arrangement. The central core is connected with peripheral doublets of microtubules by fine radial fibers. An observation of cross-section of a duct containing sperm reveals 
numerous cross sections of spermatozoa. Some of them display only a single axoneme (Figs.8, 9, 10, 13); two axonemes with nucleus, mitochondrion and ring of peripheral microtubules (Fig. 12); two axonemes with nucleus (Fig. 12) or two axonemes without nucleus (Fig. 11); two axonemes with or without mitochondrion (Fig. 11); the microtubules sheath interrupted around the axoneme (Fig. 11) and a complete ring of cortical microtubules around the axonemes (Figs., 11,12). It is interesting that transversal section in sperm is composed of 4 axonemes (Fig.10).

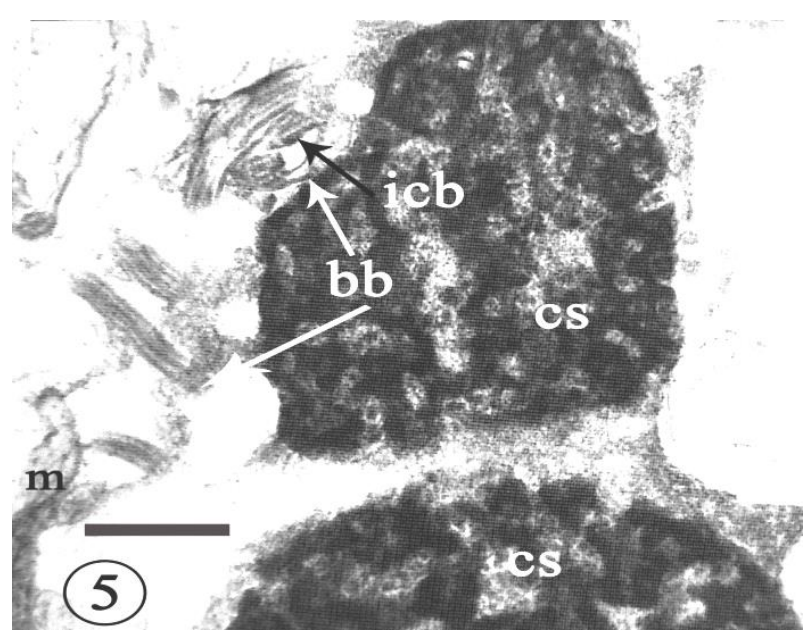

Fig. 5. Spermiogenesis of Pricea sp.: Transversal and longtudinal sections showing differentiating spermatids are connected to common cytoplasmic mass (cs), mitochondrionia $(\mathrm{m})$, and late spermatid with basal bodies (bb) and axonemes either side of the intercentriolar body (icb). Scale bar $=0.5 \mu \mathrm{m}$.

It will be seen from transverse sections (Figs.8, 9, 11, 12, 13) of Pricea sp. that at one end of the sperm contain only the main axoneme whereas transverse sections at the opposite end of the sperm contain two axonemes with nucleus and a complete ring of cortical microtubules around the axonemes. Previous authors (e.g Justine and Mattei, 1984) have regarded the centriolar end of the sperm as "anterior" and this convention will be followed in the present account. The main region of spermatozoon contains the two axonemes the nucleus, the mitochondrion and a row of microtubules, which support the plasma membrane. At the posterior extremity of the spermatozoon, the nucleus was found to be accompanied by two axonemes and a complete ring of cortical microtubules (Fig. 12). Some spermatozoa profiles containing both axonemes were observed with a lateral flange (Fig. 8). This protuberance, formed from a fold of the plasma membrane, did not exhibit any external ornamentation. The flange was observed on either the left or right side of each spermatozoon, but no bilateral projections were recorded

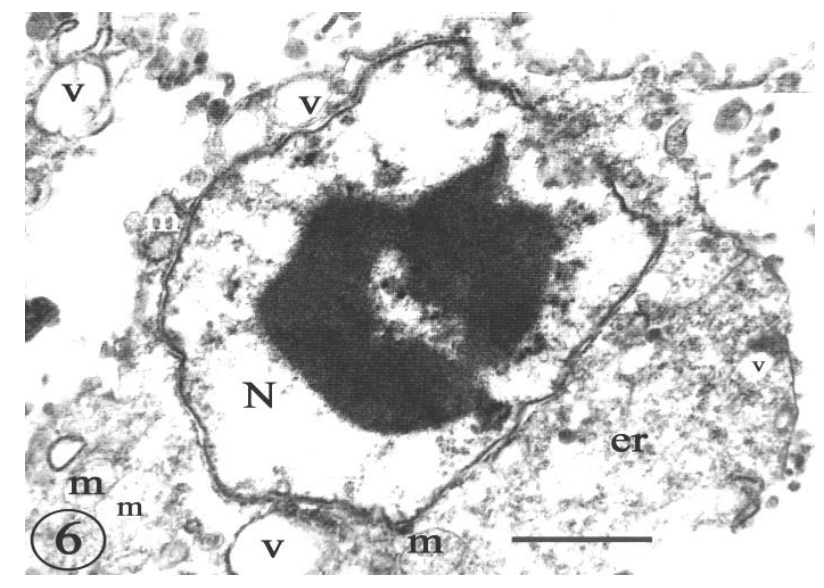

Fig. 6. Spermiogenesis of Pricea sp. A - Early spermatid with prominent nucleus (N) and mitochondria (m). Endoplasmic reticulum (er), free ribosomes and numerous vesicles (V) fill the granular cytoplasm. Scale bar $=0.5 \mu \mathrm{m}$.

\section{Discussion}

The present study indicated that spermiogenesis and the structure of the filiform sperm of Pricea sp. conform to the typical polyopisthocotylean pattern. The main characteristics of this spermatozoon are the presence of one mitochondrion, two axonemes, of the $9+$ " 1 " pattern, which are of unequal length, and the cortical microtubules extend almost the entire length of the spermatozoon. The spermatozoa of Pricea sp. have a plesiomorphic structure (two free axonemes) and in this respect, they cope with to the pattern found in other polyopisthocotylean monogeneans, digeneans and aspidogastreans (Justine et al. 1993, Watson 1997, Cable and Tinsly, 2001). Justine et al. (1985) distinguished four patterns of spermatozoa in the Monogenea. Their pattern I ,characterized by two axonemes and a row of cortical microtubules, is presumed to be the ancestral one from which the remaining three 
patterns are derived: pattern 2 by the reduction of the cortical microtubules, pattern 3 through the loss of one of the two axonemes and most of the cortical microtubules and pattern 4 by means of the reduction of one axoneme and all cortical microtubules.

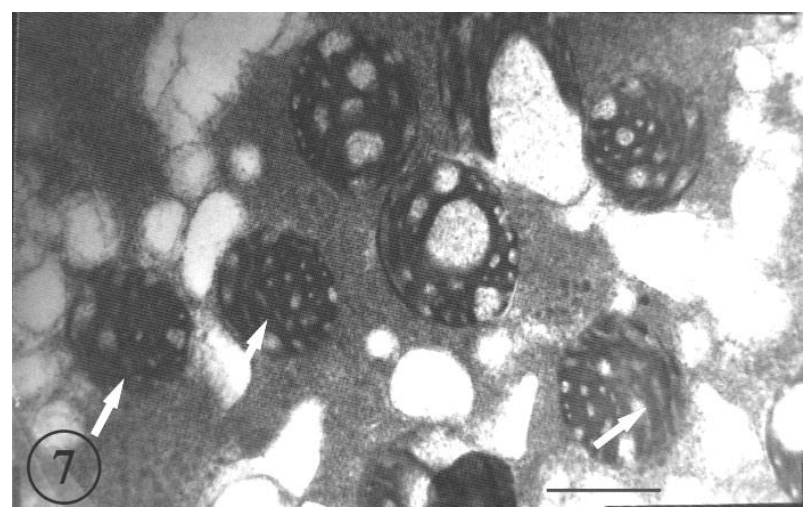

Fig. 7. Spermiogenesis of Pricea sp. Spermatids undergoing nuclear condensation. Fine granules (arrows) amongst the characteristic scroll-like configurations of chromatin, Scale bar $=0.5 \mu \mathrm{m}$.

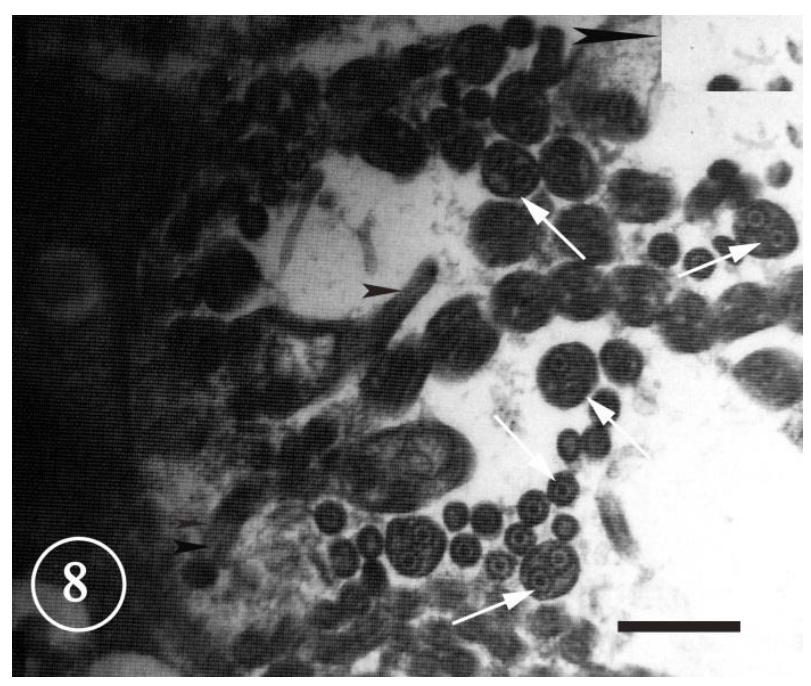

Fig. 8. Spermiogenesis of Pricea sp. whorls of mature spermatozoa (arrows) tend to lie internally Note. Lateral protrusion (arrow heads) of mid-region of late spermatid (immature spermatozoa). Scale bar $=0.5 \mu \mathrm{m}$.

Spermiogenesis in Pricea sp. in the present study, involves: 1) formation of zones of differentiation on the cytophore surface, characterised by two free flagella derived from basal bodies, 2) elongation of the nucleus and mitochondrion into the developing sperm body. It is likely that gametes of Pricea sp. undergo the typical mitotic and meiotic cell divisions producing 64 spermatids from each cluster. The number of spermatids produced during each cycle of spermatogenesis is variable among monogeneans but it is 64 in most species (Justine et al. 1993, Watson 1997).

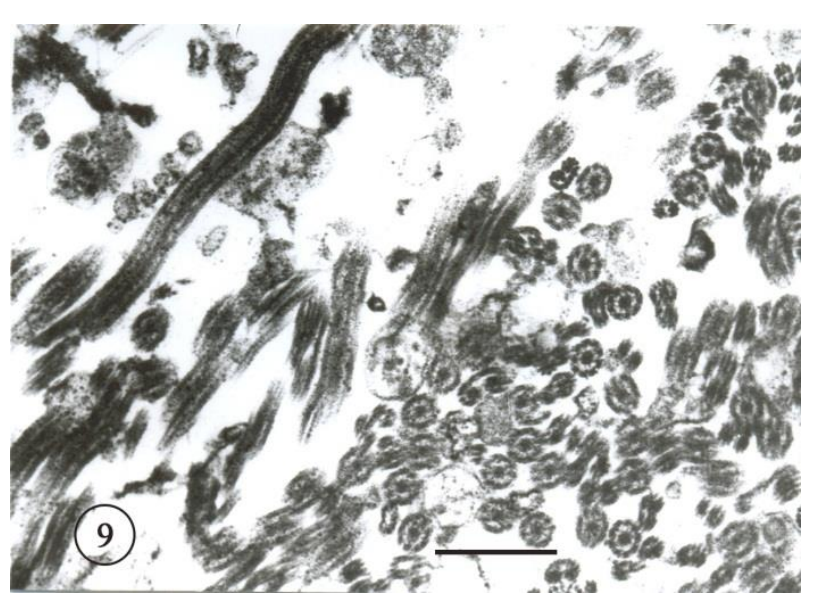

Fig. 9. Longitudinal and transversal sections of spermatozoa of Pricea sp. A single axial unit with $9+$ " 1 ". Scale bar $=0.5 \mu \mathrm{m}$.

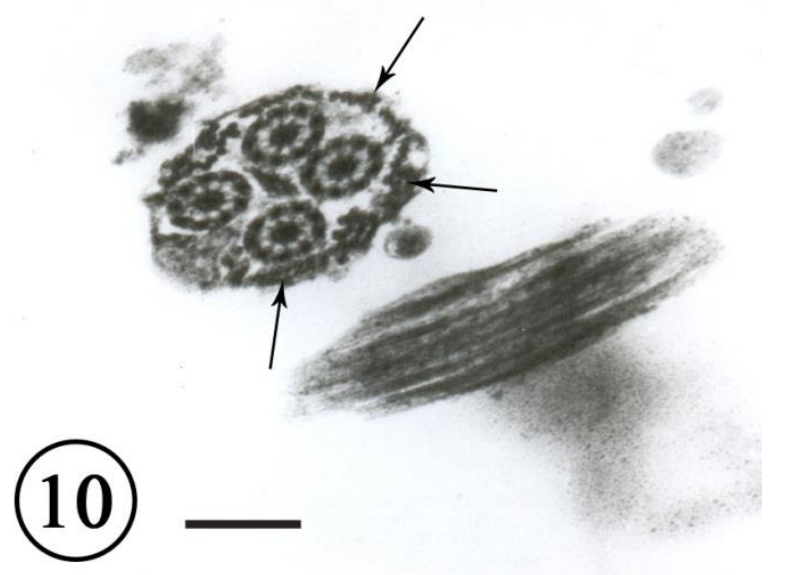

Fig. 10. Longitudinal and transversal sections of spermatozoa of Pricea sp. showing a complete ring of cortical microtubules around 4 axonemes (arrows). Scale bar $=0.2 \mu \mathrm{m}$.

The persent study reveals the presence of unulating membrane restricted to a short region of the spermatozoon. Undulating membranes are 
found in the polyopisthocotyleans Concinnocotyla australensis (see Watson et al. 1995), Gotocotyla acanthura (see Justine and Mattei 1985), Gonoplasius sp. (see Rohde and Watson 1994), was detected in Discocotyle. sagittata sperm by Cable and Tinsley (2001) and in the monopisthocotylean Macrogyrodactylus polypteri by Schmahl and Elwasila ( 1992). Undulating membranes are found in the aspidogastreans Multicotyle purvisi (see Watson and Rohde 1995) and Lobatostoma manteri (see Rohde et al. 1991). The undulating membrane of platyhelminth sperm probably contributes to spermatozoan mobility (Justine and Mattei 1985). Watson et al. (1995) suggested that the position of undulating membranes might be of phylogenetic significance.

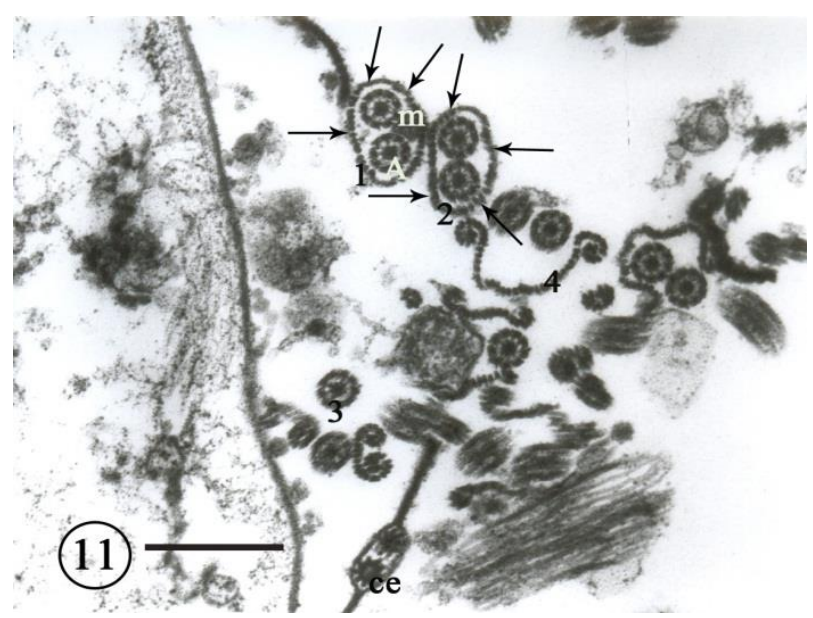

Fig. 11. longitudinal and transversal sections of spermatozoa of Pricea sp. showing: , 1), two axonemes with mitochondrion, 2) only two axonemes; 3) single axoneme; 4) the microtubules sheath interrupted and a complete ring of cortical microtubules around the axonemes ( arrows), A, axial unit; ce, centriole. Scale bar $=0.5 \mu \mathrm{m}$.

The unusual transverse profile of 4 axonemes in Pricea sp. sperm, under investigation, is interesting phenomena. Mackinnon and Burt (1984) found 1 to 8 axonemes in the sperm of pseudophyllidean cestode Botbrimonus sturionis. This corresponds to the increased number of axonemes in mature sperm of for which four kinds of explanation are possible 1) it may be an artifact, which - however - is unlikely since fixation seems to be good; 2) it may be due to natural disintegration and fusion of aging sperm; 3) it may be due to back folding of sperm along part of its length; 4) it may be genuinely multi-axonemal. In many cases, however, natural aging is possible explanation of large numbers of disintegrating sperm in the vicinity of spermatozoa with increased numbers of axonemes.

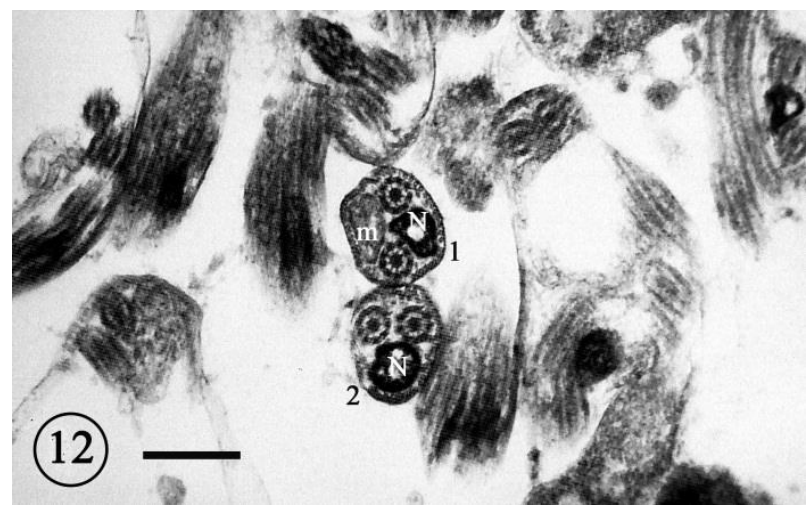

Fig. 12. Longitudinal and transversal sections of spermatozoa showing: 1), two axonemes with mitochondrion and nucleus; 2), two axonemes with nucleus , nucleus $(\mathrm{N})$, mitochondrion $(\mathrm{m})$ Scale bar $=0.2 \mu \mathrm{m}$.

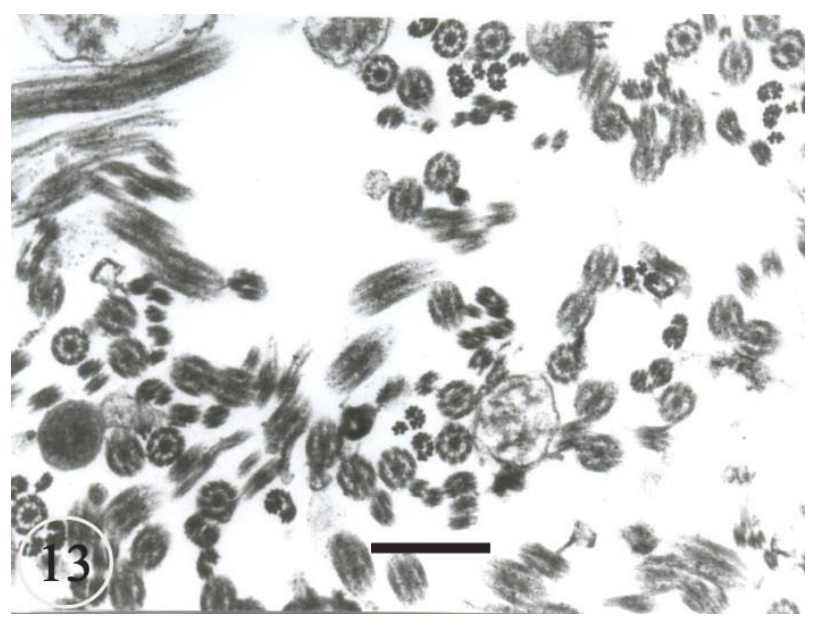

Fig. 13. Longitudinal and transversal sections of spermatozoa of Pricea sp. Scale bar $=0.5 \mu \mathrm{m}$.

Undulating membranes are found in the polyopisthocotyleans Concinnocotyla australensis (see Watson et al. 1995), Gotocotyla acanthura (see Justine and Mattei1985), Gonoplasius sp. (see Rohde and Watson 1994), are not found in the current study. The absence of undulating 
membranes in the polyopisthocotylean Pricea sp. under investigation needs to be confirmed in further study.

Nuclear location in parasitic platyhelminths is a matter of controversy, but the nucleus tends to be described as posterior as this region is last to enter the oocyte during fertilization (Justine 1995, Justine and Mattei 1984). Alternatively, the anteroposterior orientation of spermatozoa is expressed in proximal-distal terms, the distal tip of the spermatid defined during spermiogenesis with respect to the cytophore (e.g. Ishida et al. 1991). The nucleus of Pricea sp. under investigation extends to the posterior location.

The present study has revealed the presence of cortical microtubules extending under the plasma membrane along the length of the spermatozoon. Justine et al. (1985) found that sperm pattern 2 of a capsalid species is brought about by the loss of the cortical microtubules at the beginning of the spermiogenesis and concluded that sperm pattern 2 is derived from pattern 1 . This is in turn indicates that the capsalids have an early type of sperm pattern 2, and likewise that the capsalids represent an early intermediate step in monogenean evolution. Bayoumy and Abd El- Monem (2011) found that, certain transverse sections of Lamellodiscus diplodicus showed microtubules inside the sperm membrane. Similar finding were reported by Justine and Mattei (1985) in case of monopithcotylean parasite, Loimosina wilsoni; by Bayoumy et al. 2005) in case of Pseudohaliotrema plectocirra and by Levron et al. (2009) in case of the diphyllobothriidean worm, Ligula intestinalis. Bayoumy and Abd El- Monem (2011) considered the cortical microtubules of Lamellodiscus diplodicus as reinforcement elements.

\section{References}

Bâ, C.T. and Marchand, B. (1995): Spermiogenesis, spermatozoa and phyletic affinities in the Cestoda. Mém. Mus. natn .Hist. nat., $166: 87-95$.

$\mathrm{Ba}^{\wedge}$, C. T., Ndiaye, P. I., Dione, A., Quilichini, Y. and Marchand. B. (2011): Ultrastructure of the spermatozoon of Holorchis micracanthum (Digenea: Lepocreadiidae), an intestinal parasite of Plectorhinchus mediterraneus (Pisces, Teleostei) in Senegal. Parasitol. Res. 109: 1099-1106.

Bayoumy E.M., Abd El-Monem, S. (2011): Surface Topography and Spermiogenesis of Lamellodiscus
Diplodicus (Monogenea, Diplectanidae), A Parasite of Gerres Oyena (teleostei, Gerridae) from The Suez Gulf, Egypt. Life Science Journal .8(3): 467 476.

Bayoumy E.M., Abd El-Monem S., Hassanain, M.A. (2005): Ultrastructural observations of spermatogenesis and spermiogenesis in the fish-gill fluke, Pseudohaliotrema plectocirra Paperna, 1972 (Ancyrocephalinae, Monogenea). Journal of Veterinary Medical Association. 65(4):259- 267.

Boeger, W.A., Kritsky, D.C. (1993): Phylogeny and a revised classification of the Monogenoidea Bychowsky, 1937 (Platyhelminthes). Syst. Parasitol. 26: 1-32.

Brooks, D.R., (1989) A summary of the data base pertaining to the phylogeny of the major groups of parasitic platyhelminths, with a revised classification. Can. J. Zool., 67 :714-720.

Brooks, D. R., and McLennan, D. A. (1993): Macroevolutionary patterns of morphological diversification among parasitic flatworms (Platyhelminthes: Cercomeria). Evolution 47: 495509.

Brooks, D. R., O’Grady, R. T. and Glen, D. R.(1985): The phylogeny of the Cercomeria Brooks, 1982 (Platyhelminthes). Proc. Helminthol. Soc. Wash. 52: $1-20$.

Cable J. and Tinsley R. C. ( 2001) : Ultrastructure of spermiogenesis and spermatozoa of Discocotyle sagittata (Monogenea: Polyopisthocotylea: Discocotylinea) FOLIA PARASITOL. 48: 209-216,

Ehlers, U. (1985): Phylogenetic relationships within the Platyhelminthes. In: The Origins and Relationships of Lower Invertebrates, S. Conway Morris, J.D. George, R. Gibson and H.M. Platt (eds.), Oxford University Press, Oxford, pp. 143-158.

Euzet, L., Swiderski, Z. and Mokhtar-Maamouri, F. (1981): Ultrastructure comparée du spermatozoide des cestodes. Relations avec la phylogénèse. Ann. Parasitol., 56 : 247-259.

Hoberg, E. P., Mariaux, J. Justine, J.-L. Brooks, D. R. and Weekes, P. J. (1997); Phylogeny of the orders of the Eucestoda (Cercomeromorphae) based on comparative morphology: historical perspectives and a new working hypothesis. J. Parasitol. 83: 1128-1147.

Ishida S., Yamashita Y., Teshirogi W. 1991:Analytical studies of the ultrastructure and movement of the spermatozoa of freshwater triclads. Hydrobiologia 227: 95-104.

Justine J.-L. (1991a): Cladistic study of the Monogenea (Platyhelminthes), based upon a parsimony analysis of spermiogenetic and spermatozoal characters. Int. J. Parasitol. 21: 821-838.

Justine J.-L.(1991b): Spermatozoa as a tool for taxonomy of species and supraspecific taxa in the 
Platyhelminthes. In: B. Baccetti (Ed.), Comparative Spermatology 20 Years After. Raven Press, New York, pp. 981-984.

Justine J.-L. (1993a) : Phylogénie des Monogènes basée surune analyse de parcimonie des caractères de l'ultrastructure de la spermiogénèse et des spermatozoïdes incluant les résultats récents. Bull. Fr. Pêche Piscic. 328: 137-155.

Justine J.-L. (1993b) : Ultrastructure of the Monogenea: lists of investigated species and organs. Bull. Fr. Pêche Piscic. 328: 156-188.

Justine, J.-L. (1995): Spermatozoal ultrastructure and phylogeny in the parasitic Platyhelminthes. Mém. Mus. natn. Hist. nat., 166 55-86.

Justine, J.-L., (1997): La classification générale des Plathelminthes parasites: changements récents et utilisation des caractères ultrastructuraux, en particulier des spermatozoïdes.Bull. Soc. zool. Fr., 122 269-277.

Justine, J.-L., (2001): Spermatozoa as phylogenetic characters for the Platyhelminthes. In: Interrelationships of the Platyhelminthes, D.T.J. Littlewood and R.A. Bray (eds.), Taylor\& Francis, New York, , pp. 231-238.

Justine J.-L., Afzelius B.A., Malmberg G., Matteix. (1993): Ultrastructure of spermiogenesis in Acanthocotyle and Myxinidocotyle (Platyhelminthes, Monogenea, Acanthocotylidae). Acta Zool. (Stockh.) 74: 119-126.

Justine J. L., Lambert, A., Mattei, X. (1985): Spermatozoon ultrastructure and phylogenetic relationships in the monogeneans (Platyhelminthes). Int. J. Parasitol. 15: 601-608.

Justine J.-L., Mattei, X. (1984): Comparative ultrastructural study of spermiogensis in monogeneans (flatworms). 4. Diplectanum (Monopithocotylea , Diplectanidae). J. Ultrastruct. Res. 88: 77-91.

Justine J.-L., Mattei, X. (1985): A spermatozoon with undulating membrane in a parasitic flatworm, Gotocotyla(Monogenea, Polyopisthocotylea, Gotocotylidae). J. Ultrastruct. Res. 90: 163-171.

Levron, C., Miquel, J. M. Oros, and T. Scholz. (2010): Spermatozoa of tapeworms (Platyhelminthes, Eucestoda): advances in ultrastructural and phylogenetic studies. Biol. Rev. 85: 523-543.

Levron C., Sitko J., Scholz T. (2009): Spermatogenesis and spermatozoon of the tapworm Ligula intestinalis (Diphyllobothriidea): Phyllogenetic implecations. Journal of Parasitology. 95 (1) 1-9.
Littlewood, D. T. J., Rohde, K. and Clough, K. A. (1998): The phylogenetic position of Udonella (Platyhelminthes). Int. J. Parasitol. 28: 1241-1250.

Mackinnon, B. M., Burt, M. D. B. (1984): The comparative ultrastructure of permatozoa from Bothrimonus sturionis Duv. 1842 (Pseudophyllidea), Pseudanthobothrium hanseni Baer, 1956 (Tetraphyllidea), and Monoecocestus americanus Stiles, 1895 (Cyclophyllidea), Can. J. Zoo]. 62: 1059-1066.

Olson, P. D., ,Cribb, T. H., Tkach, V. V., Bray, R. A. and Littlewood, D. T. J . (2003): Phylogeny and classification of the Digenea (Platyhelminthes: Trematoda). Int. J. Parasitol. 33: 733-755.

Olson, P. D., and Tkach, V. V. (2005): Advances and trends in the molecular systematics of the parasitic platyhelminthes. Adv. Parasitol.60: 165-243.

Reynolds, E.S., (1963): The use of lead citrate at high $\mathrm{pH}$ as an electron-opaque stain in electron microscopy. J. Cell Biol., 17: 208-212.

Rohde, K., (1990): Phylogeny of Platyhelminthes, with special reference to parasitic groups. Int. J. Parasitol., 20 979-1007.

Rohde K., Watson, N.A. (1994): Spermiogenesis in Gonoplasius sp. (Platyhelminthes, Monogenea, Polyopisthocotylea, Microcotylidae). Acta Parasitol. 39: $111-116$.

Rohde K., Watson, N.A. and Cribb, T. (1991): Ultrastructure of sperm and spermatogenesis of Lobatostoma manteri (Trematoda, Aspidogastrea). Int. J. Parasitol. 21: 409-419.

Schmahl G., Elwasila M. (1992): Fine structure of spermatogenesis in monopisthocotylean monogeneans (Macrogyrodactylus polypteri, Pseudodactylogyrus bini). Folia Parasitol. 39: 19-31.

Watson N.A. (1997): Spermiogenesis and sperm ultrastructure in Troglocephalus rhinobatidis, Neoheterocotyle rhinobatidis and Merizocotyle australensis (Platyhelminthes, Monogenea, Monopisthocotylea, Monocotylidae). Int. J. Parasitol. 27: 389-401.

Watson N.A., Rohde K. (1995): Re-examination of spermiogenesis of Multicotyle purvisi (Platyhelminthes, Aspidogastrea). Int. J. Parasitol. 25: 579-586.

Watson N.A., Whittington I.D., Rohde K. (1995): Ultrastructure of spermiogenesis and spermatozoa in the monogeneans Concinnocotyla australensis (Polystomatidae) and Pricea multae (Gastrocotylidae). Parasite 1995: 357-366. 
الملخص العربى

التركيب الدقيق لتكوين الحيوانات المنوية ووصف الحيوان المنوى البالغ للطفيلى وحيد العائل من جنس

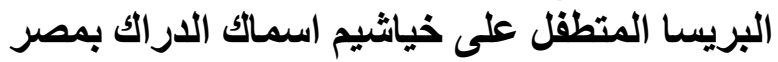

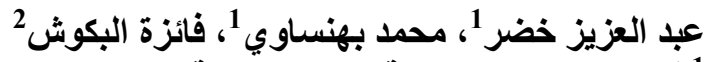

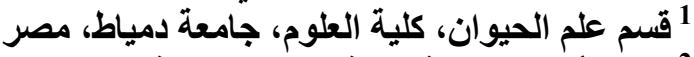
2قسم الأحياء المائية، كلية العلوم، جامعة جامعة المرقب، ليبياط

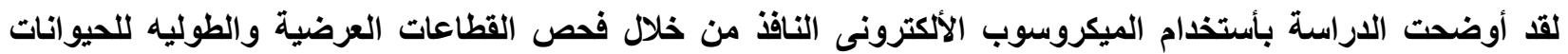

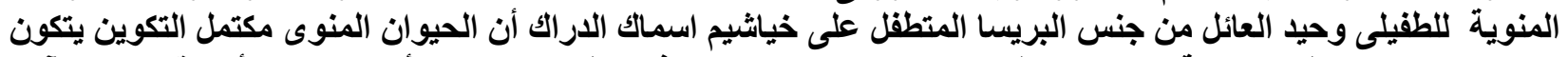

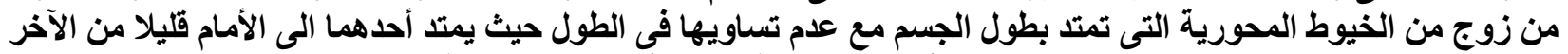

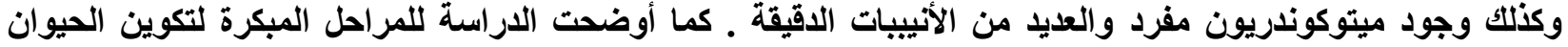

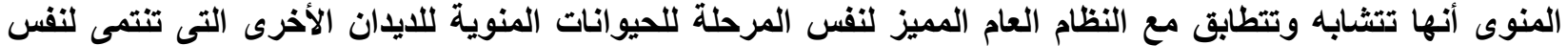

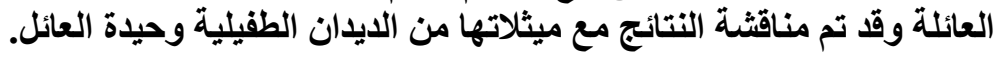

